\title{
Kajian Pengaruh Penggunaan Zat Admixture " X", Fiber Dan Semen Grouting Terhadap Kuat Tekan Dan Retak Beton Pada Beton Tanpa Perawatan
}

\author{
Aland Surya Nugroho ${ }^{1}$, Theovilla Arry ${ }^{2}$ \\ email: alandsurya.n@gmail.com ${ }^{1}$ \\ theovillasfs@gmail.com² \\ ${ }^{1,2}$ Universitas Katolik Soegijapranata; Jl. Pawiyatan Luhur IV/1 Bendan Dhuwur Semarang 50234, \\ 024-8441555 \\ ${ }^{3}$ Program Studi Teknik Sipil, Fakultas Teknik, Unika Soegijapranata, Semarang
}

\begin{abstract}
Abstrak
Saat ini, banyak ditemukan kerusakan pada struktur beton pada bangunan yang telah berdiri. Salah satu kerusakan tersebut adalah munculnya retak. Retak pada beton disebabkan karena banyak faktor, antara lain beban yang melebihi batasan, suhu, komponen material penyusun, proses pelaksanaan pembuatan beton dan waktu.

Penelitian ini dilakukan dengan tujuan mengkaji pengaruh penggunaan zat admixture " $\mathrm{x}$ ", fiber dan semen grouting terhadap kuat tekan dan retak beton pada beton tanpa perawatan. Benda uji dalam penelitian ini berbentuk pelat beton dengan ukuran $1 \mathrm{~m} \times 1 \mathrm{~m}$ dengan tebal $6 \mathrm{~cm}$, silinder ukuran $\varnothing$ $15 \mathrm{~cm}$ dengan tinggi $30 \mathrm{~cm}$, mutu beton rencana K $250(20,75 \mathrm{MPa})$, viscocrete, fiber jenis monofilament polypropylene, dan semen grouting.

Hasil penelitian ini menunjukkan bahwa penambahan fiber dapat meminimalkan munculnya retak pada beton. Selain itu juga meningkatkan kuat tekan beton yaitu K 295 (24,5 MPa). Penggunaan viscocrete justru menimbulkan retak paling banyak apabila tidak dilakukan perawatan, namun memiliki kuat tertinggi yaitu K 340 (28,3 MPa).
\end{abstract}

Kata kunci : pelat, beton, retak, tanpa perawatan, bahan tambah

\begin{abstract}
At present, there are many damages to concrete structures in buildings that have build. One such damage is the appearance of cracks. Cracks in concrete are caused by many factors, including loads that exceed limits, temperature, components of the constituent material, the process of making concrete and time.

This research was conducted with the aim of studying the effect of the use of admixture " $x$ ", fiber and cement grouting on the compressive strength and cracking of concrete in untreated concrete. The specimens in this study are in the form of a concrete slab with a size of $1 \mathrm{~m} \times 1 \mathrm{~m}$ with a thickness of $6 \mathrm{~cm}$, cylinder size $\emptyset 15 \mathrm{~cm}$ with a height of $30 \mathrm{~cm}$, concrete quality plan $\mathrm{K} 250(20,75 \mathrm{MPa})$, viscocrete, fiber type monofilament polypropylene, and cement grouting.

The results of this study indicate that the addition of fiber can minimize the appearance of cracks in concrete. In addition, it also increases the compressive strength of concrete, namely K 295 (24,5 $\mathrm{MPa}$ ). The use of viscocrete actually causes the most cracks if not cured, but has the highest strength, namely $\mathrm{K} 340(28,3 \mathrm{MPa})$.
\end{abstract}

Keywords: slab, concrete, cracks, without curing, admixtures 


\section{PENDAhuluan}

Beton adalah bahan konstruksi yang terbuat dari campuran agregat halus dan agregat kasar dengan semen sebagai bahan pengikat serta air. Perkembangan pembangunan infrastruktur yang semakin pesat membutuhkan inovasi teknologi beton untuk menjawab tantangan akan kebutuhan. Beton yang dihasilkan diharapkan mempunyai kualitas tinggi, meliputi kekuatan dan daya tahan, tanpa mengabaikan nilai ekonomis. Menurut (Standar Nasional Indonesia) SNI 036468-2-00 beton mutu tinggi (high strength concrete) mempunyai kuat tekan yang disyaratkan lebih besar atau sama dengan $f c^{\prime} 40 \mathrm{MPa}-80 \mathrm{MPa}$. Beton mutu tinggi dapat diperoleh dengan menggantikan atau menambah bahan tambah dalam proses pembuatan beton sesuai dengan ketentuan. Tujuannya untuk mengubah sifat beton antara lain: mempercepat pengerasan, meningkatkan workability, menambah kuat tekan, mengurangi sifat getas serta mengurangi retak-retak.

Penelitian ini bertujuan membandingkan hasil kuat tekan dan retak beton untuk campuran beton yang ditambah bahan tambah dan campuran beton normal. Benda uji dalam kondisi tanpa perawatan. Pengujian pada penelitian ini untuk kuat tekan benda uji dalam bentuk silinder. Pengamatan retak benda uji dalam bentuk pelat. Pengujian kuat tekan dan pengamatan retak beton dilaksanakan dalam usia 7, 14 dan 28 hari.

\section{TUJUAN}

Tujuan dalam penelitian ini untuk mengetahui dampak pemakaian zat admixture viscocrete, fiber dan semen pada keretakan beton tanpa perawatan serta mengetahui perbedaan nilai kuat tekan beton biasa, beton dengan campuran zat admixture viscocrete serta beton dengan campuran fiber.

\section{TINJAUAN PUSTAKA 3.1 Beton}

Beton merupakan campuran antara semen portland atau semen hidrolik yang lain, agregat halus, agregat kasar dan air, dengan atau tanpa bahan tambahan yang membentuk massa padat (SNI-03-28472002).

Beton normal merupakan beton yang mempunyai berat isi antara 2200 sampai dengan $2500 \mathrm{~kg} / \mathrm{m}^{3}$ dengan bahan penyusun air, pasir, semen portland dan batu alam baik yang dipecah atau tidak, tanpa menggunakan bahan tambahan (SNI 03-2834-2000).

Menurut Sutikno (2003) kelebihan dan kekurangan beton meliputi:

1. Kemudahan dalam mencetak

2. Memiliki nilai ekonomis

3. Bersifat awet dan tahan lama

4. Tahan api

5. Efisiensi energi

6. Pengecorannya sangatlah mudah dan dapat dicor di tempat.

Kekurangan beton sebagai berikut :

1. Kuat tarik beton sangatlah rendah, sehingga memerlukan baja tulangan agar tidak terjadinya retak pada beton akibat gaya tarik.

2. Pada saat mengering beton segar akan mengerut atau susut dan akan mengembang apabila beton keras terkena air atau basah.

3. Beton sulit untuk kedap air secara sempurna, sehingga memungkinkan air masuk ke dalam beton.

4. Beton memiliki sifat getas, sehingga pada saat perencanaan haruslah dihitung secara teliti dan benar. Supaya setelah digabungkan dengan baja tulagan akan memiliki kekuatan 
yang kokoh, yang terutama memiliki kekuatan untuk menahan gaya gempa.

\subsection{Bahan Penyusun Beton}

Beton tersusun dari beberapa material, yairu agregat halus, agregat kasar, semen, dan air. Beton berkualitas dan bermutu baik ditentukan dari pemilihan bahan pembentuk beton yang akan digunakan, perhitungan mix design yang tepat, cara pengerjaan beton dan proses perawatan beton.

Material yang akan digunakan dalam pembuatan campuran beton perlu dilakukan pengujian untuk memenuhi standar yang telah ditentukan.

Bahan tambah diperlukan untuk menyesuaikan beberapa sifat beton biasanya campuran beton diberikan bahan tambah (admixture) agar mutu beton yang direncanakan dapat tercapai.

Bahan Tambah campuran beton antara lain :

\section{a. Admixture}

Bahan tambah kimia (chemical admixture) yang digunakan dalam penelitian ini adalah Sika Viscocrete. Admixture tersebut termasuk tipe $\mathrm{F}$ "Water Reducing High Range Admixtures". Dosis yang dipakai adalah $0,9 \%$. Yang memiliki masa jenis $1,06 \mathrm{~kg} / \mathrm{L}$.

Fungsinya untuk mengurangi jumlah air yang dipakai dalam adukan beton. Sehingga dapat meningkatkan kuat tekan beton yang dihasilkan. Pada peneltian ini digunakan viscocrete hasil produksi dari Sika, yaitu Sika Viscocrete 1003. Dengan menggunakan jenis viscocrete ini, maka beton yang dihasilkan termasuk kategori self compacting concrete (SCC).

b. Semen Grouting

Penelitian ini menggunakan semen yang biasanya dipakai untuk pekerjaan grouting, yang merupakan produksi
Sika yaitu SikaGrout 215. Spesifikasi SikaGrout 215 adalah sebagai berikut:

1. Compressive Strength: $712 \mathrm{Kg} / \mathrm{cm}^{2}$

2. Flexural Strength: $58,6 \mathrm{Kg} / \mathrm{cm}^{2}$

c. Fiber atau Serat

Fiber yang digunakan dalam penelitian ini adalah fiber dengan jenis polypropylene, yang merupakan produk SikaFibre yang diproduksi oleh PT. Sika. Serat SikaFibre adalah serat monofilament polypropylene mikro yang didesain khusus untuk meminimalisir dan mengontrol retak akibat susut plastis (plastic shrinkage). Data teknis dari serat SikaFibre adalah sebagai berikut:

Bahan :

Serat polypropylene dengan surface agent, berwarna :Natural / Putih , berat Jenis : $0,91 \mathrm{gr} / \mathrm{cm}^{3}$, panjang Serat : 12 $\mathrm{mm}$, diameter Serat : 18 mikronnominal, kuat Tarik : 300-440 MPa, modulus Elastisitas $\quad: 6000-9000$ $\mathrm{MPa}$

\subsection{Kerusakan Beton}

Kerusakan pada beton dikelompokkan dalam tiga katagori yaitu:

a. Retak (cracks)

Retak (cracks) adalah pecah pada beton dalam garis-garis yang relatif panjang dan sempit (Mangkoesoebroto, 1998). Penyebab retak pada pelat beton diantaranya adalah komposisi cor yang kurang sempurna, perubahan suhu yang sangat ekstrem, proses curring yang kurang sempurna, terkena terkena sinar matahari secara langsung serta pembebanan pelat saat kondisi pengecoran belum kering.

Macam-macam penyebab retak beton:

1. Plastic cracking

Retak yang diakibatkan karena evaporasi air dalam campuran beton terjadi dengan cepat akibat 
cuaca yang panas, kering atau berangin.

2. Concrete Crazing

Retak ini jarang lebih dalam dari 3 $\mathrm{mm}$, dan lebih terlihat pada permukaan yang tergenang secara berlebihan. Retak craze berkembang pada usia dini dan terlihat jelas sehari setelah penempatan atau setidaknya pada akhir hari pertama, tidak mudah terlihat sampai permukaan telah dibasahi dan mulai kering.

3. Drying Shrinkage Cracking

Susut akibat pengeringan disebabkan dari kehilangan kadar air dari campuran semen, yang dapat menyusut hingga $1 \%$. Beton juga cenderung mengembang ketika dibasahi (peningkatan volume bisa sebanding dengan besarnya penyusutan beton).

4. Cracking due to Chemical Reaction

Reaksi kimia yang bersifat merusak dapat menyebabkan retak pada beton. Reaksi ini mungkin terjadi karena bahan yang digunakan untuk membuat beton atau material lain yang bertemu dengan beton setelah beton kering. Beton dapat pecah seiring dengan waktu akibat reaksi ekspansif yang berkembang secara perlahan antara agregat yang mengandung silika aktif dan basa yang berasal dari hidrasi semen, admixture atau sumber eksternal (misalnya air curing, air tanah, dan alkaline yang ditaruh atau digunakan pada pada permukaan beton yang sudah kering).

b. Voids

Voids adalah lubang-lubang yang relatif dalam dan lebar pada beton
(Mangkoesoebroto, 1998). Void pada beton disebabkan karena pemadatan yang dilakukan dengan vibrator kurang baik, karena jarak antar bekisting dengan tulangan atau jarak antar tulangan terlalu sempit sehingga bagian mortar tidak dapat mengisi rongga antara agregat kasar dengan baik. Void yang berupa lubang-lubang tidak teratur disebut honey combing.

c. Scalling/spalling/erosion

Scalling adalah kelupasan dangkal pada permukaan, yang dapat ditimbulkan karena eksposisi yang berulang-ulang terhadap pembekuan dan pencairan sehingga permukaan terkelupas.

\subsection{Uji Kuat Tekan}

Kekuatan tekan beton dapat dipengaruhi oleh perbandingan air, agregat kasar dan agregat halus serta berbagai jenis campuran lainnya. Kekuatan beton berdasarkan teori perbandingan faktor air semen (f.a.s) apabila memenuhi syarat sebagai berikut (Surdia dan Saito, 1984):

1. Cara uji dan kualitas semen yang digunakan adalah sama.

2. Agregat memiliki kekuatan yang tinggi.

3. Betonnya mampat.

4. Beton bersifat plastis dan dapat diolah

Kekuatan tekan adalah kemampuan beton untuk menerima gaya tekan persatuan luas. Kuat tekan beton merupakan salah satu identifikasi mutu dari sebuah struktur beton. Semakin tinggi kekuatan struktur dikehendaki, semakin tinggi pula mutu beton yang diperlukan (Mulyono, 2004).

Rumus yang digunakan untuk mengetahui kuat tekan beton adalah :

$f c^{\prime}=\frac{P}{A^{\prime}}$

Keterangan : 
$f_{c}$, = kuat tekan beton $\left(\mathrm{N} / \mathrm{mm}^{2}=\right.$ $\mathrm{MPa})$

$\mathrm{P} \quad=$ beban tekan $(\mathrm{N})$

$\mathrm{A}^{\prime}=$ luas penampang daerah tekan $\left(\mathrm{mm}^{2}\right)$

\section{METODE PENELITIAN}

Berikut merupakan bagan alir untuk memperjelas tahapan penelitian yang dapat dilihat pada Gambar 1.

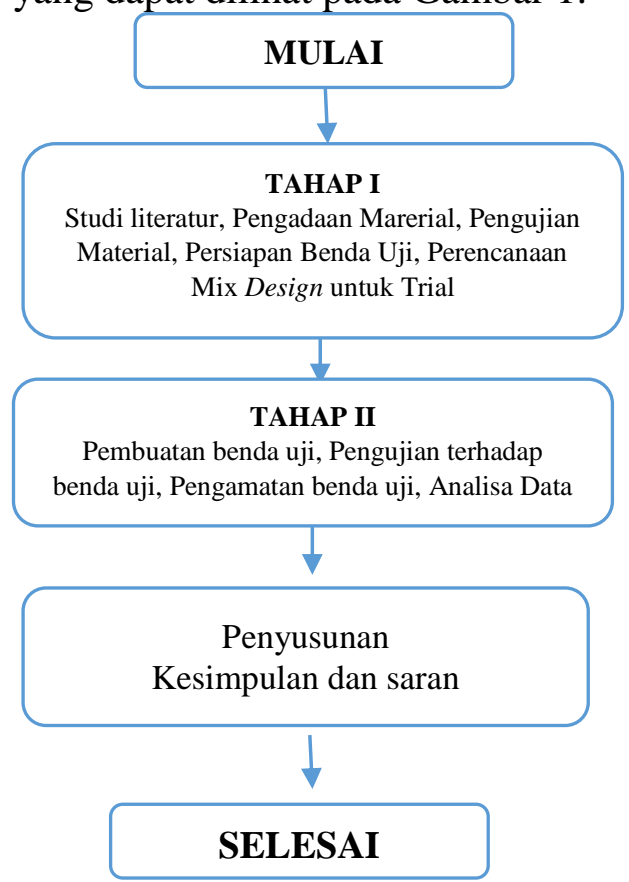

Gambar 1. Bagan Alir Tahapan Penelitian

\section{ANALISIS DATA DAN PEMBAHASAN}

\subsection{Hasil Pengujian Kuat Tekan}

Pengujian Kuat Tekan pada penelitian ini menggunakan benda uji silinder berukuran diameter $15 \mathrm{~cm}$ dan tinggi $30 \mathrm{~cm}$.

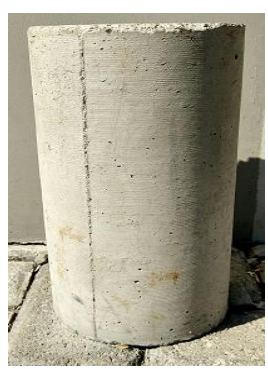

Gambar 2. Benda uji Silinder

Pengujian kuat tekan yang dilakukan dengan alat Universal Testing Machine. beban maksimum diperoleh pada saat benda uji mengalami keruntuhan akibat menerima pembebanan (Pmax). Benda Uji pada penelitian ini berjumlah 36 buah dengan 4 variasi penambahan bahan tambah utnuk campuran beton. Benda uji terdiri dari 9 untuk beton normal, 9 benda uji dengan tambahan admixture, 9 benda uji dengan tambahan semen grouting dan 9 benda uji dengan tambahan fiber. Pada Gambar 3. diperlihatkan grafik Gaya tekan rata-rata hasil uji kuat tekan . Benda uji dites kuat tekannya ada usia beton 7 hari, 14 hari dan 28 hari masing masing variasi 3 sampel.

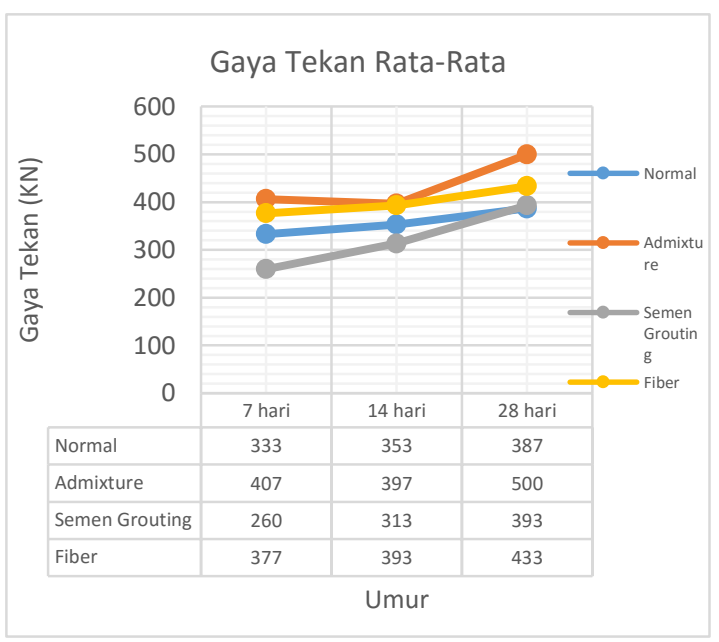

Gambar 3. Grafik Gaya Tekan Rata-Rata 
Berdasarkan Gambar 3 dapat diketahui bahwa keseluruhan kekuatan beton yang dihasilkan mengalami peningkatan kekuatan seiring dengan bertambahnya umur beton tersebut. Beton dengan bahan tambah viscocrete memiliki kekuatan tekan yang paling tinggi. Sejak umur 7 hari sudah memiliki gaya tekan $407 \mathrm{KN}$. Dan pada beton umur 28 hari kekuatannya mencapai $500 \mathrm{KN}$. Sedangkan benda uji dengan lapisan semen grouting pada permukaan atasnya memiliki kuat tekan yang rendah yaitu sebesar $393 \mathrm{KN}$. Kuat tekan beton pada umur 28 hari yang terendah adalah beton normal dengan nilai kuat tekan $387 \mathrm{KN}$.

Perbedaan kuat tekan bisa saja dikarenakan material yang digunakan, bahan tambah yang dicampurkan pada saat proses pengadukan hingga proses pembuatan atau pencetakan benda uji. Rendahnya nilai kuat tekan pada benda uji dengan semen grouting pada umur 7 hari serta 2 buah benda uji dengan bahan tambah viscocrete pada umur 14 dan 28 hari, bisa disebabkan karena proses pengerjaan pencetakan benda uji yang kurang tepat. Terutama pada proses pemadatannya yang kurang benar. Sehingga kuat tekan yang dihasilkan menjadi rendah. Sehingga dapat disimpulkan bahwa faktor manusia terutama pada proses pengerjaannya memiliki pengaruh besar terhdapa kualitas yang akan dihasilkan oleh beton tersebut.

Gaya tekan yang dihasilkan oleh beton pada umur 28 hari semuanya diatas dari hasil hasil yang diinginkan yaitu 367 $\mathrm{KN}$ (K 250), meskipun beton tersebut tidak mengalami perawatan. Jadi bisa disimpulan bahwa tanpa perawatan tidak menurunkan nilai kuat tekan beton. Asalkan beton tersebut dibuat dengan baik yaitu pada saat pelaksaan maupun saat perhitungan mix design dan pemilihan material penyusun beton.

\subsection{Hasil Pengamatan Retak Plat beton}

\section{$1 \mathrm{~m} \times 1 \mathrm{~m} \times 6 \mathrm{~cm}$}

Pengamatan Retak Plat beton $1 \mathrm{~m} \times 1 \mathrm{~m} \times$ $6 \mathrm{~cm}$ yang diperlihatkan pada gambar 3 dilakukan pada beton berumur 7 hari, 14 hari dan 28 hari.

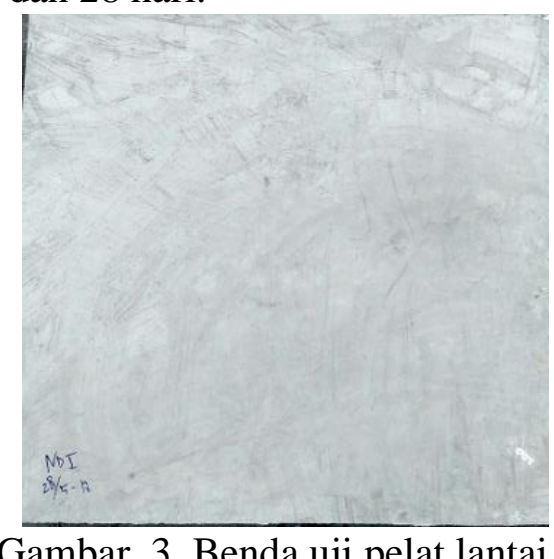

Gambar 3. Benda uji pelat lantai

Pengamatan dilakukan untuk beton normal, beton dengan tambahan admixture viscocrete, semen grouting dan fiber. Pada Gambar 4 diperlihatkan Grafik Perbandingan Panjang Retak Pelat Beton.

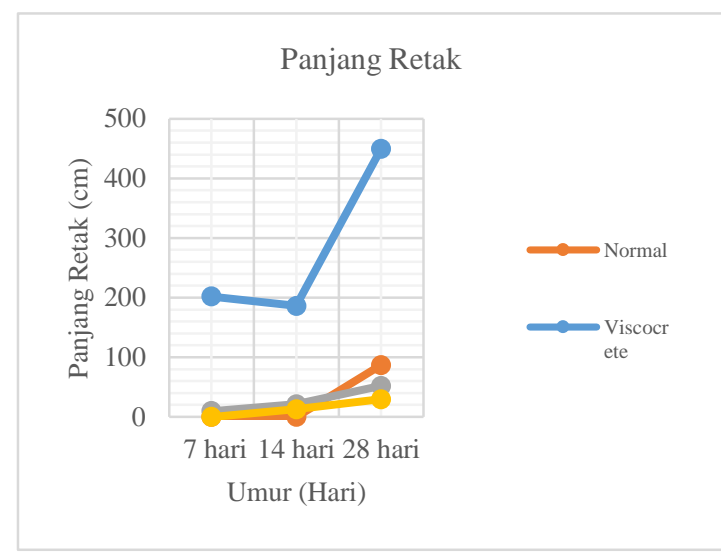

Gambar 4. Grafik Perbandingan Panjang Retak Pelat Beton 
Dari gambar 4. dapat diketahui bahwa pelat beton pada umur 28 hari dengan menggunakan bahan tambah fiber dengan jenis fiber monofiament polypropylene menghasilkan muncul retak yang paling sedikit daripada bahan yang lain yaitu $29,7 \mathrm{~cm}$. Selain itu, pelat beton dengan bahan tambah viscocrete 1003 justru menghasilkan retak yang paling banyak yaitu 449,7 cm. Sehingga dapat disimpulkan bahwa beton dengan bahan tambah bahan kimia perlu perawatan yang lebih hati-hati seperti penyiraman atau curing secara berkala, pemadatan dilakukan dengan benar. Untuk menghasilkan beton dengan mutu dan karakeristik yang baik pula. Apabila perawatannya tidak maksimal akan muncul masalah dikemudian hari.

Pelat beton dengan bahan tambah fiber memiliki panjang retak yang paling sedikit, karena didalam adukan beton tersebut terdapat fiber yang berguna untuk meningkatkan kohesi antar bahan penyusun beton. Pada saat terjadi retak, tidak akan langsung retak melainkan tertahan terlebih dahulu oleh fiber tersebut.

Pelat beton dengan bahan tambah semen grouting memiliki panjang retak sedikit, karena semen goruting sendiri merupakan bahan yang butirannya kecil, sehingga rongganya sangat rapat. Selain itu, semen grouting sendiri tahan terhadap penyusutan.

Pelat beton dengan normal cukup banyak terjadi retak. Terlebih jika pelat beton tersebut terkena cuaca secara langsung. Terkena sinar matahari atau air hujan secara terus menerus membuat keawetan beton tersebut menjad berkurang. Apabila ingin diletakkan pada cuaca secara langsung maka permukaan beton perlu dilindungi. Bisa dengan menambah fiber atau bisa juga dengan pelapisan cat atau bahan kedap lainnya.

Pelat beton dengan bahan tambah admixture viscocrete terjadi banyak retak. Hal ini terjadi karena dengan adanya viscocrete trsebut membuat kandungan air dalam beton sangat minim. Tanpa adanya air curing pada saat proses pengerasan (terjadi panas hidrasi yang cukup tinggi) membuat kandungan air dalam beton cepat menguap. Yang membuat permukaan beton mudah terjadinya retak. Oleh sebab itu, apabila ingin mendapatkan hasil yang maksimal dari zat tersebut, maka diperlukan perawatan bisa dengan penyiraman, pemberian kain basah atau produk yang lain.

\section{PENUTUP}

\subsection{Kesimpulan}

Kesimpulan yang didapat berdasarkan dari hasil penelitian yang sudah dilakukan adalah sebagai berikut:

1. Retak pada beton pasti akan muncul seiring dengan berjalannya waktu, apalagi beton tersebut tidak dilakukan perawatan (curing) saat proses pengerasan. Terlebih beton tersebut terkena cuaca seperti sinar matahari atau air hujan secara langsung. Yang menurunkan keawetan beton itu sendiri.

2. Kuat tekan beton pada umur 28 hari dengan benda uji silinder diperoleh hasil:

a. Tertinggi adalah K 341 (28,3 MPa), yaitu beton dengan bahan tambah viscocrete 1003.

b. Terendah adalah K 264 (21,9 MPa), yaitu beton tanpa bahan tambah.

3. Pengamatan retak pada pelat beton diperoleh hasil:

a. Total panjang retak terbanyak adalah pelat beton dengan bahan 
tambah viscocrete, yaitu sepanjang $837,7 \mathrm{~cm}$.

b. Total panjang retak tersedikit adalah pelat beton dengan bahan tambah fiber dengan jenis fibernya adalah monofilament polypropylene, yaitu sepanjang $42,5 \mathrm{~cm}$.

4. Bahan yang tepat untuk mengurangi munculnya retak adalah fiber. Jumlah fiber yang digunakan yaitu sebanyak $600 \mathrm{gr} / \mathrm{m}^{3}$. Fiber dapat mengurangi retak akibat shrinkage dan dapat meningkatkan kuat tekan. Fiber di dalam adukan beton berfungsi untuk meningkatkan kohesi. Yang membuat ikatan antar bahan penyusun beton menjadi lebih kuat, sehingga meminimalisir munculnya retak pada beton.

5. Beton dengan bahan tambah viscocrete mempunyai kuat tekan yang tinggi karena mengurangi pemakaian air pada adukan beton. Banyaknya viscocrete yang digunakan yaitu $0,9 \%$ dari cement content. Namun memiliki retak yang cukup banyak saat tanpa perawatan.

6. Beton dengan pelapisan semen grouting juga memiliki retak yang relatif sedikit, pada umur 28 hari hanya muncul sebesar $51,98 \mathrm{~cm}$. Penggunaan semen grouting yaitu setebal $\pm 1 \mathrm{~mm}$. Sehingga dengan adanya pelapisan lagi pada permukaan beton akan membuat beton minim retak dan beton menjadi semakin awet. Selain itu semen grouting sendiri tahan terhadap penyusutan.

7. Retak yang muncul pada pelat beton kemungkinan disebabkan adanya perbedaan tegangan pada permukaan atas beton dengan permukaan bawah beton.

\subsection{Saran}

Saran merupakan elemen yang penting bagi kelanjutan sebuah penelitian. Agar penelitian selanjutnya menghasilkan karya yang jauh lebih baik lagi. Saran untuk penelitian yang akan datang antara lain :

1. Pada beton yang terkena cuaca secara langsung perlu dilapisi lagi bagian permukaannya atau menggunakan bahan bahan tambah dalam adukan beton. Untuk meningkatkan keawetan beton itu sendiri dan meminimalisir munculnya retak.

2. Perlu dilakukan variasi terhadap viscocrete untuk mengetahui dampak pada kuat tekan yang dihasilkan serta keretakan yang akan muncul.

3. Perlu dilakukan variasi terhadap panjang fiber dan jumlah fiber untuk mengetahui dampak pada kuat tekan yang dihasilkan serta keretakan yang akan muncul.

4. Perlu dilakukan penelitian di tempat yang memiliki suhu lebih panas. Penelitian ini dilakukan di wilayah yang berada di dataran yang lumayan tinggi yaitu berkisar $470 \mathrm{~m}$ diatas permukaan laut (berdasarkan data dari Google Earth), sehingga suhu di sekitar lebih sejuk.

5. Perlu adanya variasi agregat kasar pada campuran beton.

6. Perlu adanya variasi jumlah penggosokan pada pelat untuk mengatahui dampaknya pada retak yang muncul.

7. Perlunya perawatan pada beton degan bahan tambah viscorete, agar mendapat hasil yang maksimal.

8. Perlu adanya perbandingan terhadap beton dengan perawatan.

9. Perlu adanya pelapisan lagi pada bekisting menggunakan lembaran plastik, dimaksudkan untuk 
meminimalisir perbedaan tegangan pada permukaan pelat beton.

10. Perawatan beton harus dilakukan secara berkala dan sesuai prosedur untuk meningkatkan keawetan beton.

\section{DAFTAR PUSTAKA}

Annual Book of ASTM Standard. 2002. ASTM C-494-86 Standard Specifications for Chemical Admixtures for Concrete. United States of America. http://www.astm.org/cgibin/resolver.cgi?C494C494M-17 [diakses pada Juli 2018].

Annual Book of ASTM Standard. 2002. ASTM C 31 Practice for Making and Curing Concrete Test Specimens in the Field. United States of America. http://www.astm.org/cgibin/resolver.cgi?C31C31M-18b [diakses pada Juli 2018].

Annual Book of ASTM Standard. 2002. ASTM C 125 Standard Terminology Relating to Concrete and Concrete Agregates. United States of America. http://www.astm.org/cgibin/resolver.cgi?C125-18a [diakses pada Juli 2018].

Annual Book of ASTM Standard. 2002. ASTM C 150 Standard Specification for Portland Cement. United States of America. http://www.astm.org/cgibin/resolver.cgi?C150C150M-18 [diakses pada Juli 2018].

Annual Book of ASTM Standard. 2002. ASTM C 192 Practice for Making and Curing Concrete Test Specimens in the Laboratory. United States of America. http://www.astm.org/cgi-
bin/resolver.cgi?C192C192M-16a [diakses pada Juli 2018].

Anonim. 2016. Tujuan dan Metode Perawatan Beton (curing). http://www.hilongeotextile.com/tujua n-dan-metode-perawatan-betoncuring/ [diakses pada Mei 2018].

Anonim. 2017. Kenali Beda Jenis Retak pada Bangunan. http://www.solusiholcim.com/dekor/ kenali-beda-jenis-retak-padabangunan [diakses pada Juli 2018].

Antono, Ahmad. 1989. Beton Tulangan. Yogyakarta: Andi Offset.

Badan Standarisasi Nasional. 1989. SK SNI S-04-1989-F : Spesifikasi Bahan Bangunan Bagian A, Bahan Bangunan Bukan Logam. Jakarta:BSN.

Badan Standarisasi Nasional. 2000. SNI 03-2834-2000 : Tata Cara Pembuatan Rencana Campuran Beton Normal. Jakarta:BSN.

Badan Standarisasi Nasional. 2000. SNI 03-6468-2000 : Tata Cara Perencanaan Campuran Tinggi Dengan Semen Portland Dengan Abuterbang. Jakarta:BSN.

Badan Standarisasi Nasional. 2002. SNI 03 - 2847 - 2002 : Tata Cara Perencanaan Struktur Beton Untuk Bangunan Gedung. Jakarta:BSN.

Chu-Kia Wang, Salmon Charles G. 1993. Disain Beton Bertulang. Jakarta: Elrangga.

Gambhir, M.L. 1986. Concrete Technology. New Delhi: Tata McGraw-Hill Publishing Company Limited. 
Hartono. 2013. Studi Kuat Tekan Beton Dengan Agregat Kasar Dari Batu Kapur. Jurnal Gema Teknologi Vol 17 No 3 Periode April 2013 - Oktober 2013.

Haque,M.N. 1998. Give It a Week : 7 days Initial Curing. Jurnal International Concrete Edisi September.

Mangkoesoebroto, P Sindur. 1998. Jenisjenis Kerusakan pada Struktur Beton Bertulang. Bandung: Laboratorium Mekanika Struktur PAU Ilmu Rekayasa , Institut Teknologi Bandung.

Mayavani, Christine dan Habudin. 2006. Pengaruh Perawatan Beton Terhadap Kuat Tekan Dan Absorpsi Beton K300. Skripsi Program Studi Teknik Sipil. Universitas Diponegoro.

Mindess, S., Young, J.F., dan Darwin, D. 2003. Concrete second edition. London:Pearson Education Ltd.

Mulyo,T. 2003. Teknologi Beton. Yogyakarta: Fakultas Teknik UGM.

Mulyono, Tri. 2005. Teknologi Beton. Yogyakarta: Andi.

Murdock, L.J. dan K.M Brook. 1991. Bahan dan Praktek Beton Edisi Keempat. Diterjemahkan oleh Stepanus Hendarko. Jakarta: Erlangga.

Murdock, L.J. dan K.M Brook. 1999. Bahan Praktek Beton. Diterjemahkan oleh Stepanus Hendarko. Jakarta: Erlangga.

Nawy, Edward, G. 1990. Beton Bertulang. Bandung: PT. Eresco.
Neville, A. M. 2002. Properties of Concrete Fourth Edition. Harlow,England: Pearson Education.

Nugraha, Paul dan Antoni. 2007. Teknologi Beton. Yogyakarta: Andi.

PBI 1971 N.I.-2. 1979. Peraturan Beton Bertulang Indonesia 1971. Direktorat Penyelidikan Masalah Bangunan. Bandung.

Samekto, Wuryati dan Rahmadiyanto, Candra. 2001. Teknologi Beton. Yogyakarta: Kanisius.

Supit, Fransiska Verent., Pandeleke, Ronny., Dapas, Servie O. 2016. Pemeriksaan Kuat Tarik Belah Beton Dengan Variasi Agregat Yang Berasal Dari Beberapa Tempat Di Sulawesi Utara. Jurnal Ilmiah Media Engineering Vol. 6 No. 2 Mei 2016 (476-484).

Sutandar, Erwin. 2013. Pengaruh Pemeliharaan (Curing) Pada Kuat Tekan Beton Normal. Jurnal Vokasi Volume IX, Nomor 2, Juli 2013 (8999).

Sutikno. 2003. Panduan Praktek Beton. Surbaya: Universitas Negeri Surabaya.

Surdia, Tata dan Saito, Shinroku. 1984. Pengetahuan Bahan Teknik. Jakarta: PT. Pradnya Paramita.

Tjokrodimuljo, Kardiyono. 1996. Teknologi Beton. Yogyakarta: Nafiri 